\title{
Photochemistry and Vibrational Spectra of Matrix-Isolated 5-Ethoxy-1-Phenyl-1H-Tetrazole
}

\author{
Luís M. T. Frija, ${ }^{\dagger,}$ I. D. Reva, ${ }^{\ddagger}$ A. Gómez-Zavaglia,,$\$$ M. L. S. Cristiano, and R. Fausto \\ Department of Chemistry and Biochemistry, F.C.T., and CCMAR, University of Algarve, Campus de Gambelas, \\ 8005-039 Faro, Portugal, Department of Chemistry, University of Coimbra, Coimbra, P-3004-535, Portugal, \\ and Faculty of Pharmacy and Biochemistry, University of Buenos Aires, C.P. 1113 Buenos Aires, Argentina
}

Received: December 13, 2006; In Final Form: January 29, 2007

\begin{abstract}
A combined matrix isolation FT-IR and theoretical DFT(B3LYP)/6-311++G(d,p) study of the molecular structure and photochemistry of 5-ethoxy-1-phenyl-1H-tetrazole (5EPT) was performed. A new method of synthesis of the compound is described. Calculations show three minima, very close in energy and separated by low-energy barriers (less than $4 \mathrm{~kJ} \mathrm{~mol}^{-1}$ ), in the ground-state potential energy profile of the molecule. The method of matrix isolation enabled the reduction of the number of populated conformational states in the experiment at low temperature due to the effect known as conformational cooling. As a result, the spectrum of the as-deposited matrix of 5EPT closely matches that of the most stable conformer predicted theoretically, pointing to the existence of only this conformer in the low-temperature matrixes. In this structure, the dihedral angle between the two rings, phenyl and tetrazole, is ca. $30^{\circ}$, whereas the ethyl group stays nearly in the plane of the tetrazole ring and is as far as possible from the phenyl group. In situ UV irradiation $(\lambda>235$ $\mathrm{nm}$ ) of the matrix-isolated 5EPT induced unimolecular decomposition, which led mainly to production of ethylcyanate and phenylazide, this later compound further reacting to yield, as final product, 1-aza-1,2,4,6cycloheptatetraene. Anti-aromatic 3-ethoxy-1-phenyl- $1 \mathrm{H}$-diazirene was also observed experimentally as minor photoproduct, resulting from direct extrusion of molecular nitrogen from 5EPT. This species has not been described before and is now characterized by infrared spectroscopy for the first time.
\end{abstract}

\section{Introduction}

Much attention has been devoted to tetrazole-based compounds due to their wide range of practical applications. The tetrazolic acid fragment, $-\mathrm{CN}_{4} \mathrm{H}$, exhibits physical characteristics similar to those of the carboxylic acid group, $-\mathrm{CO}_{2} \mathrm{H}$, but is metabolically more stable. ${ }^{1}$ Therefore, the design of surrogate compounds bearing $-\mathrm{CN}_{4} \mathrm{H}$ groups instead of $-\mathrm{CO}_{2} \mathrm{H}$ in biologically active molecules is a commonly followed approach, for instance in medicinal chemistry. ${ }^{2}$ The free $\mathrm{N}-\mathrm{H}$ bond of tetrazoles makes them acidic molecules, and not surprisingly it has been shown that both the aliphatic and aromatic heterocycles have $\mathrm{p} K_{\mathrm{a}}$ values that are similar to those of the corresponding carboxylic acids (4.5-4.9 vs 4.2-4.4, respectively), due to the ability of the tetrazole moiety to stabilize a negative charge by electron delocalization. ${ }^{3-7}$ In general, tetrazolic acids are strongly influenced by the effect of substituents at the $\mathrm{C}_{(5)}$-position. ${ }^{4}$ It has been held that 5-substituted-1H-tetrazoles $\left(\mathrm{RCN}_{4} \mathrm{H}\right)$ may serve as a nonclassical isostere for the carboxylic acid moiety $\left(\mathrm{RCO}_{2} \mathrm{H}\right)$ in biologically active molecules. ${ }^{4,8-13}$ The term "nonclassical isosterism" (used interchangeably with the term "bioisosterism") refers to the concept in which functional groups that have similar physicochemical properties may be interchangeable, resulting in similar biological properties. In fact, the number of patent claims and publications related to medicinal uses of tetrazoles continues to grow rapidly. ${ }^{14-19}$ In addition, tetrazoles also show applications in agriculture,${ }^{20}$ in photography and photoimaging, ${ }^{21}$ and in the automobile industry as gas-generating agents for airbags. ${ }^{22}$

\footnotetext{
* Corresponding author. E-mail: rfausto@ci.uc.pt.

University of Algarve.

$\doteqdot$ University of Coimbra.

$\S$ University of Buenos Aires.
}

The extensive applications of tetrazole-based compounds stimulated research in areas such as the design of synthetic methodologies and the reactivity of various tetrazolyl derivatives. From the viewpoint of reactivity, tetrazoles are also really interesting compounds. For instance, they have been shown to exhibit a very rich photochemistry, which was found to be strongly influenced by the nature of the substituents present on the tetrazole ring. ${ }^{23,24}$ Also, the relative flexibility of the tetrazole moiety to the introduction of diverse substituents leads to a large diversity of photoproducts upon photolysis, including biologically important heterocyclic ring systems other than tetrazoles. ${ }^{25,26}$

In spite of the importance and wealth of applications of tetrazoles, very little attention has been given in the past to the study of this family of compounds at a monomeric level. Recently, a research program aiming to fill this gap was started in our laboratories. The molecular structure, tautomerism, vibrational spectra, and photochemistry of unsubstituted tetrazole and some of its representative derivatives were investigated within the framework of this project by a concerted approach, using matrix isolation infrared spectroscopy and high-level DFTbased theoretical calculations. ${ }^{27-33}$

The use of matrix isolation technique, coupled to a suitable probing method (e.g., FT-IR spectroscopy), represents an appropriate approach to improve our understanding of the photochemistry of tetrazole derivatives. The useful simplification for the study of the mechanisms of photoreaction is that the products of unimolecular photochemistry are cage-confined and molecular diffusion is inhibited, precluding cross-reactions involving fragments photoproduced from a different reactant molecule from taking place. Besides, the studied guest molecules do not rotate when they are embedded in a solid matrix host at 
low temperature (usually 10-15 K), and additionally, when the matrix environment is inert (typically argon), the effects of inhomogeneous broadening of the vibrational bands are minimized. Consequently, the vibrational bands in the spectra of matrix-isolated compounds become very sharp and narrow. Thus the matrix isolation approach makes possible the achievement of a considerably high spectroscopic resolution, which increases the probability of detecting chemical species produced in low amounts during photolysis or those having IR absorptions of intrinsically low intensity. Furthermore, due to the high resolution of the method, it is possible to distinguish spectral signatures of different tautomers or conformers, which are usually closely located in the spectrum (typically, within a few wavenumbers). An additional advantage results from the fact that the lowtemperature conditions can be used for trapping and spectroscopic identification of, at least, some of the intermediate transient products. Finally, due to the high resolution of the method, it becomes possible to compare directly the experimental spectra with the results of theoretical calculations.

In view of the widespread interest in tetrazole-based compounds (in particular 5-substituted tetrazoles), and continuing our research program on the photochemistry of tetrazolyl derivatives, 5-ethoxy-1-phenyl-1H-tetrazole (5EPT) was selected as the subject of the present investigation. Hence, in this work, 5-EPT was synthesized and its structure, vibrational spectra, and UV-induced photochemistry were studied by matrix isolation infrared spectroscopy, supported by extensive DFT(B3LYP)/6-311++G(d,p) calculations.

\section{Materials and Methods}

Synthesis of 5-Ethoxy-1-phenyl-1H-tetrazole (5EPT). Diverse methodologies to synthesize 5-alkoxy- and 5-aryloxy-1aryltetrazoles have been described ${ }^{34,35}$ in view of the great importance of these compounds, from a synthetic point of view, as intermediates to the preparation of 1-alkyl-4-aryl-4,5-dihydro$1 H$-tetrazol-5-ones via a thermally induced Chapman isomerization. ${ }^{36,37}$ In the present study, 5EPT was prepared by a novel method, with high reaction yield. Small fragments of metallic sodium ( $\mathrm{Na}(\mathrm{s}), 1 \mathrm{~g} ; 43 \mathrm{mmol})$ were added carefully to a dry ethanol solution $(50 \mathrm{~mL})$. The mixture was stirred at room temperature under an argon atmosphere until the effervescence had ceased (10 min). 5-Chloro-1-phenyl-1H-tetrazole (1.3 g; $7.2 \mathrm{mmol})$ in dry ethanol $(20 \mathrm{~mL})$ was added, and the mixture was stirred overnight at room temperature. The reaction was monitored by thin-layer chromatography using a mixture of dichloromethane/hexane $(2: 1)$ as eluent. The deposited white precipitate was filtered and washed with ethyl acetate $(50 \mathrm{~mL})$. Ice-water $(50 \mathrm{~mL})$ was added to the combined organic extracts and the organic product extracted with ethyl acetate $(3 \times 50$ $\mathrm{mL})$. The organic phase was dried $\left(\mathrm{Na}_{2} \mathrm{SO}_{4}\right)$ and evaporated to dryness to give 5-ethoxy-1-phenyl- $1 \mathrm{H}$-tetrazole as a white solid (1.2 g; 88\% yield; mp 325-326 K). ${ }^{1} \mathrm{H}$ NMR (400 MHz, $\left.\mathrm{CDCl}_{3}\right): \delta 1.52-1.56(3 \mathrm{H}, \mathrm{t}), 4.69-4.74(2 \mathrm{H}, \mathrm{q}), 7.43-7.47$ $(1 \mathrm{H}, \mathrm{t}), 7.51-7.55(2 \mathrm{H}, \mathrm{t}), 7.72-7.74(2 \mathrm{H}, \mathrm{d}) . \mathrm{MS}(\mathrm{EI}): \mathrm{m} / \mathrm{z}$ $191(\mathrm{M}+\mathrm{H})^{+}$. The ${ }^{1} \mathrm{H}$ NMR spectrum of the compound is given in the Supporting Information.

Infrared Spectroscopy. The IR spectra of 5EPT were obtained using a Mattson (Infinity 60AR Series) Fourier transform infrared spectrometer, equipped with a deuterated triglycine sulfate (DTGS) detector and a $\mathrm{Ge} / \mathrm{KBr}$ beam splitter, with $0.5 \mathrm{~cm}^{-1}$ spectral resolution. To avoid interference from atmospheric $\mathrm{H}_{2} \mathrm{O}$ and $\mathrm{CO}_{2}$, a stream of dry nitrogen continuously purged the optical path of the spectrometer. The compound was placed in a specially designed doubly thermostatable Knudsen cell, ${ }^{38}$ whose compartments (sample container and valve nozzle) were kept at $333 \mathrm{~K}$ during deposition of the matrix. Matrixes were prepared by co-deposition, onto the CsI substrate of the cryostat cooled to $12 \mathrm{~K}$, of 5EPT vapors coming out of the Knudsen cell and a large excess of the matrix gas (argon N60, Air Liquide) coming from a separate line. All experiments were performed using an APD Cryogenics closed-cycle helium refrigeration system with a DE-202A expander.

Irradiation of the samples was carried out with a $150 \mathrm{~W}$ xenon arc lamp (Osram XBO 150W/CR OFR), through the outer $\mathrm{KBr}$ window of the cryostat $(\lambda>235 \mathrm{~nm})$.

Computational Methodology. The quantum chemical calculations of the stationary points were performed at the DFT level of theory using the standard $6-311++\mathrm{G}(\mathrm{d}, \mathrm{p})$ basis set and the three-parameter density functional abbreviated as B3LYP, which includes Becke's gradient exchange correction ${ }^{39}$ and the Lee, Yang, Parr correlation functional. ${ }^{40}$ Structural results for 5EPD are provided in Table S1 (Supporting Information). Potential energy scans were performed using the 6-31G(d,p) basis set. The nature of the obtained stationary points was checked through the analysis of the corresponding Hessian matrix.

DFT(B3LYP)/6-311++G(d,p) harmonic vibrational frequencies and IR intensities were calculated at the optimized geometries. To correct the systematic shortcomings of the applied methodology (mainly for anharmonicity), the predicted vibrational wavenumbers were scaled down by a single factor of 0.978 . The theoretical normal modes, calculated for the conformers of 5EPT ( $\mathbf{T}, \mathbf{G}$, and $\mathbf{G}^{\prime}$ ), were analyzed by calculating their potential energy distributions (PEDs) in the molecule-fixed internal coordinate system as described by Schachtschneider. ${ }^{41}$ The internal coordinates used in this analysis were defined following the recommendations of Pulay et al., ${ }^{42}$ and are listed in Table S2 (Supporting Information). The elements of potential energy distribution (PED) matrices are given in Tables S3-S5 (Supporting Information).

All calculations in this work were carried out using the Gaussian 03 program. ${ }^{43}$

\section{Results and Discussion}

DFT Structural Calculations: Molecular Geometry. The molecule of 5-ethoxy-1-phenyl- $1 H$-tetrazole has three internal rotational degrees of freedom, defined about the $-\mathrm{C}_{(6)}-\mathrm{N}_{(1)}-$, $-\mathrm{O}-\mathrm{C}_{(5)}-$, and $-\mathrm{O}-\mathrm{C}_{(18)}-$ axes, which may result in the existence of different conformers (Figure 1).

The dihedral angle around the $\mathrm{C}_{(6)}-\mathrm{N}_{(1)}$ bond defines the relative orientation of the phenyl and tetrazole rings. Calculations show that in all conformers these two rings have approximately planar geometries. However, they do not share the same plane. In all forms the inter-ring $\mathrm{CNCC}$ angle was predicted by the calculations to be ca. $30^{\circ}$ (see Table S1).

The conformers with the cis orientation of the $\mathrm{N}_{(1)}-\mathrm{C}_{(5)}-$ $\mathrm{O}_{(17)}-\mathrm{C}_{(18)}$ angle bring the ethyl and phenyl groups in a close spatial proximity and result in very high relative energies (ca. 84 and $79 \mathrm{~kJ} \mathrm{~mol}^{-1}$, for planar and nonplanar structures, respectively). Such conformers are not relevant from the experimental point of view and may be disregarded. The conformers with the trans orientation of the $\mathrm{N}_{(1)}-\mathrm{C}_{(5)}-\mathrm{O}_{(17)}-$ $\mathrm{C}_{(18)}$ angle are energetically much more stable. They may differ in the orientation of the ethyl group relative to the tetrazole ring, which is defined by the conformation around the $\mathrm{C}_{(18)}-$ $\mathrm{O}_{(17)}$ bond (see Figure 1).

The potential energy profile for internal rotation around the $\mathrm{C}_{(18)}-\mathrm{O}_{(17)}$ bond in 5EPT is shown in Figure 2. This potential 


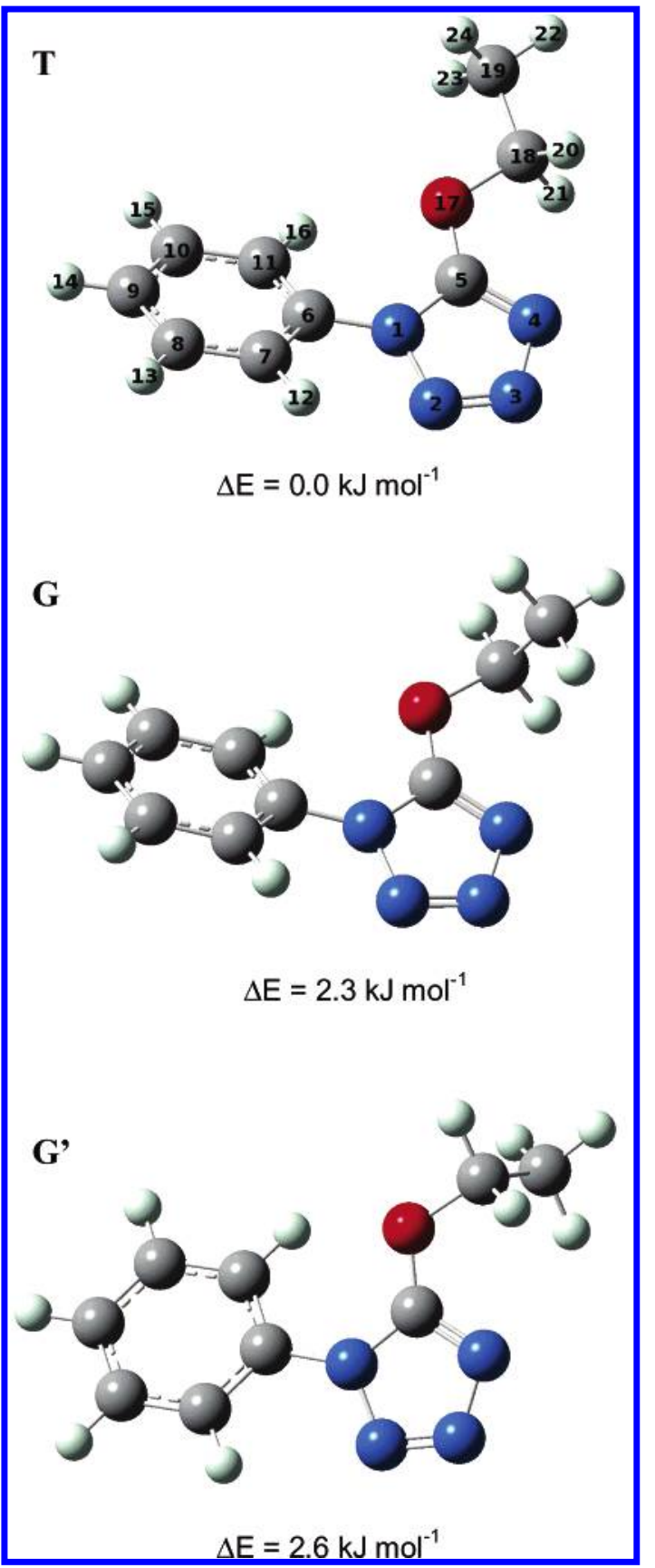

Figure 1. Optimized structures for the 5-ethoxy-1-phenyl-1 $H$-tetrazole conformers $\mathbf{T}, \mathbf{G}$, and $\mathbf{G}^{\prime}$ (with atom numbering). Relative energies calculated at the B3LYP/6-311++G(d,p) level of theory are also given (with zero point correction). Absolute calculated energy for conformer $\mathbf{T}$ is equal to $-1689043.2 \mathrm{~kJ} \mathrm{~mol}^{-1}$. Atoms $1-4$ are nitrogens, and atom 17 is oxygen.

energy profile was calculated by incrementing the value of the $\mathrm{C}_{(5)}-\mathrm{O}_{(17)}-\mathrm{C}_{(18)}-\mathrm{C}_{(19)}$ dihedral angle in steps of $20^{\circ}$ and fully optimizing all other geometric parameters. This relaxed potential energy scan revealed the existence of three local minima (see Figure 2), with relative energies falling into the $0-3 \mathrm{~kJ} \mathrm{~mol}^{-1}$ range. The most stable structure exhibits the trans orientation of the ethyl group relative to the tetrazole fragment, while the remaining conformers have the ethyl group in the \pm gauche position relative to the tetrazole ring. The energies of the latter forms (including zero point energy corrections) are 2.3 and 2.6 $\mathrm{kJ} \mathrm{mol}^{-1}$ higher than that of the most stable form.

It is logical to relate the names of different conformers to the values of the conformationally relevant dihedral angles. As

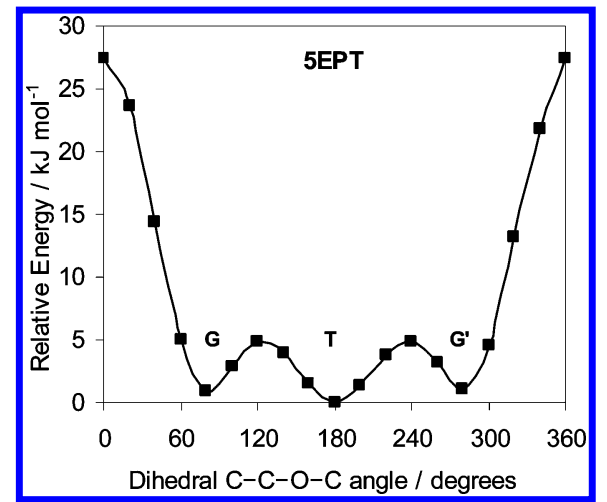

Figure 2. DFT(B3LYP)/6-311++G(d,p) calculated potential energy profile for internal rotation of the ethoxy group around the $\mathrm{C}_{(18)}-\mathrm{O}_{(17)}$ bond in 5-ethoxy-1-phenyl-1H-tetrazole. Minima denoted T, G, and $\mathrm{G}^{\prime}$ correspond to the conformers with the same names in Figure 1. The energy of the conformer $\mathbf{T}$ (the lowest energy structure) is equal to $-1689043.2 \mathrm{~kJ} \mathrm{~mol}^{-1}$ (without the ZPE contribution) and was chosen as the relative zero level.

noted above, in all experimentally relevant conformers of 5EPT the values of two of these dihedral angles (CNCC and NCOC) are nearly equal and may be conveniently omitted from the conformers' names. In this work, the names of the relevant 5EPT conformers were then assigned according to the value of the COCC dihedral angle they exhibit: $\mathbf{T}$ (trans; most stable conformer), $\mathbf{G}$ (+gauche), and $\mathbf{G}^{\prime}$ (-gauche), which are uniquely related to a COCC dihedral angle of ca. $180^{\circ},+80^{\circ}$, and $-80^{\circ}$, respectively. The optimized structures of the $\mathbf{T}, \mathbf{G}$, and $\mathbf{G}^{\prime}$ conformers of 5EPT, calculated at the DFT(B3LYP)/ $6-311++G(d, p)$ level of theory, are depicted in Figure 1. No other low-energy local minima were found.

The calculated potential energy profile shown in Figure 2 revealed that the energy barriers separating forms $\mathbf{G}$ and $\mathbf{G}^{\prime}$ from the most stable form $\mathbf{T}$ are very low, amounting to less than $4 \mathrm{~kJ} \mathrm{~mol}^{-1}$. In conformational studies of matrix-isolated molecules, the knowledge of the barriers to intramolecular rotations is very important. It is well-known that the possibility of trapping a species in the matrix is related to the barriers to intramolecular rotations separating it from lower energy species. ${ }^{44}$ If a barrier is low enough (a few kilojoules per mole), it can be surmounted even at low temperatures and the higher energy species will relax into the lower energy counterpartthe so-called conformational cooling will occur. Recently, a series of matrix isolation studies on the structure of conformationally flexible compounds was carried out in our laboratory in order to analyze the conformational cooling effect. ${ }^{45-50}$ It was shown that intramolecular energy barriers lower than $5 \mathrm{~kJ}$ $\mathrm{mol}^{-1}$ are effectively surpassed at $10 \mathrm{~K}$, already at the stage of the matrix deposition. Barriers of at least $10 \mathrm{~kJ} \mathrm{~mol}^{-1}$ are required to trap a higher energy conformer in a matrix. Thus, based on this experience, one can also assume that the same phenomenon takes place in the case of 5EPT, resulting in relaxation of the higher energy forms, $\mathbf{G}$ and $\mathbf{G}^{\prime}$, into the lowest energy conformer, $\mathbf{T}$. The experiment confirmed this expectation: Figure 3 represents the spectrum of 5EPT isolated in an argon matrix at $12 \mathrm{~K}$, which is in excellent agreement with the theoretically calculated spectrum of conformer $\mathbf{T}$.

The occurrence of the conformational cooling is a very fortunate situation, since the experimental spectrum of 5EPT is not complicated by conformational effects, which in turn will facilitate the interpretation of the photochemical processes taking place in the matrix once subjected to in situ UV irradiation $(\lambda$ $>235 \mathrm{~nm}$ ), that will be described in detail below. 


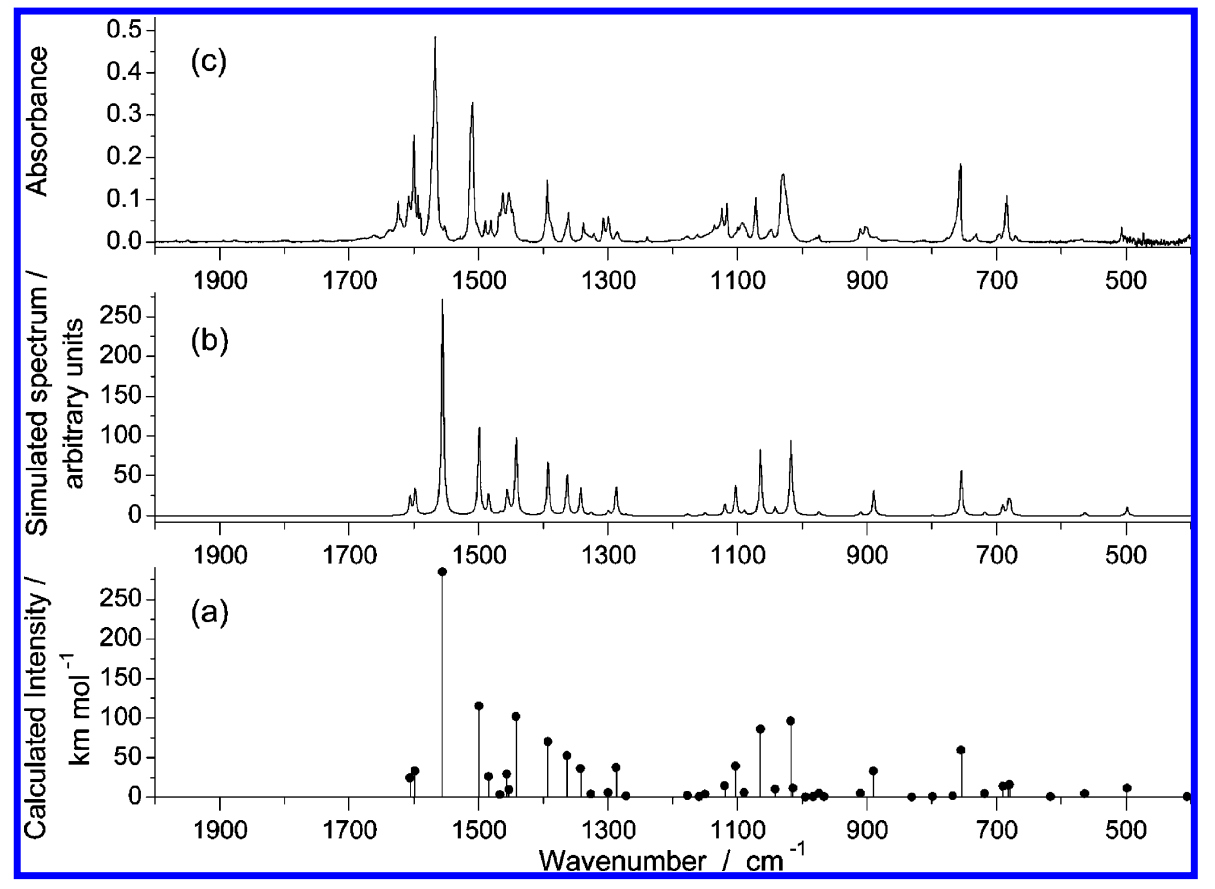

Figure 3. Infrared spectrum of $5 E P T$ in the fingerprint region: (a) Spectrum of conformer $\mathbf{T}$ calculated at the B3LYP/6-311++G(d,p) level of theory. Calculated wavenumbers were scaled by a factor of 0.978. (b) Simulated spectrum of conformer $\mathbf{T}$. It was created using Lorentzian functions centered at the calculated (scaled) frequencies [shown in (a)] and with bandwidths at half-height equal to $4 \mathrm{~cm}^{-1}$. Intensities in this spectrum were scaled arbitrarily. (c) Experimental spectrum of monomeric 5EPT trapped in an argon matrix at $12 \mathrm{~K}$.

Considering the minimum energy structure of 5EPT (conformer $\mathbf{T}$ in Figure 1), it can be easily verified that the molecule assumes a geometry in which the ethyl group stays nearly in the plane of the tetrazole ring and is situated as far as possible from the phenyl group $\left(\mathrm{C}_{(5)}-\mathrm{O}_{(17)}-\mathrm{C}_{(18)}-\mathrm{N}_{(19)}\right.$ dihedral angle $\left.\approx 180^{\circ}\right)$, with an inter-ring twisting angle of $30^{\circ}$. The value of the inter-ring angle is largely determined by the balance among three factors: (i) steric repulsion between the substituents on the tetrazole ring, which favor a nonplanar geometry; (ii) conjugation of the $\pi$ electron systems of both rings, favoring their coplanarity; and (iii) intramolecular H-bond-like interaction between the ortho-hydrogen atoms of the phenyl ring and the negatively charged $\mathrm{O}_{(17)}$ or $\mathrm{N}_{(2)}$ atoms located in the tetrazole side of the molecule $\left(\mathrm{H}_{(12)} \cdots \mathrm{N}_{(2)}\right.$ and $\mathrm{H}_{(16)} \cdots \mathrm{O}_{(17)}$ interactions can be expected to favor non-coplanar and coplanar arrangements of the two rings, respectively).

It has been verified that the first factor appears to be dominant for many molecules with two rings connected by a single bond. ${ }^{29,32,51-58}$ For instance, it is known that the chlorine substituent in 5-chloro-1-phenyl-1H-tetrazole (5CPT) is responsible for the large inter-ring angle $\left(54^{\circ}\right)$ observed for this tetrazole derivative. ${ }^{31}$ Hence, the steric effect due to the presence of the chloro substituent at $\mathrm{C}_{(5)}$ in the 5CPT molecule is clearly more important than the corresponding effect caused by the ethoxy group attached to the same position in 5EPT (inter-ring angle; $30^{\circ}$ ). In addition, the inter-ring dihedral angle in 5-methoxy-1-phenyl- $1 H$-tetrazole was found to be $29^{\circ},{ }^{29}$ i.e., smaller than in 5CPT and similar to that found for all 5EPT low energy conformers (see Table S1), indicating that in the experimentally relevant conformers of these molecules (all exhibiting the trans arrangement around the $-\mathrm{C}_{(5)}-\mathrm{O}_{(17)}-$ axis) the orientation of the ethyl substituent does not influence the interaction between the two rings.

On the other hand, in 5EPT the conjugation of the $\pi$ electron systems of phenyl and tetrazole rings does not seem to be very important, considering the estimated values for the $\mathrm{C}-\mathrm{N}$ interring distance $(142.5 \mathrm{pm})$, which can be compared with those found for alkylamines (essentially pure $\mathrm{C}-\mathrm{N}$ single bonds; within the $145-147 \mathrm{pm}$ range $)^{59}$ and, for instance, methylenimine $\left(\mathrm{H}_{2} \mathrm{C}=\mathrm{NH}\right.$, double bond; $\left.127.3 \mathrm{pm}\right) .{ }^{60}$ In simple diazines (pyrazine, pyrimidine, and pyridazine), where the $\mathrm{CN}$ bond lengths have a bond order of ca. 1.5 (conjugated system), the bond lengths are ca. $133.5 \mathrm{pm},{ }^{61-63}$ i.e., still considerably shorter than the $\mathrm{C}-\mathrm{N}$ inter-ring distance in 5-ethoxy-1-phenyl- $1 H$ tetrazole.

Infrared Spectrum of the Matrix-Isolated Compound (AsDeposited Matrix). The infrared spectrum of the matrix-isolated 5EPT is presented in Figure 3, together with the B3LYP/6$311++\mathrm{G}(\mathrm{d}, \mathrm{p})$ theoretical spectrum of conformer T. As noted above, the agreement between the experimental and calculated spectra is very good, enabling the full assignment of the experimental bands. The assignments are provided in Table 1 (results of vibrational calculations for the three conformers of 5EPT, including the definition of the used internal coordinates, are provided as Supporting Information Tables S2S5).

Conformer $\mathbf{T}$ belongs to the $C_{1}$ symmetry point group; it has 66 fundamental vibrations, all of them expected to be active in the infrared. In agreement with the spectral data previously obtained for a series of 1-phenyltetrazole based compounds, ${ }^{27,29,31,32}$ the IR spectrum of 5EPT is constituted by two groups of bands, i.e., one associated with the vibrational modes of the phenyl group and the other related to the tetrazole ring and the ethoxyl substituent.

The bands resulting from the first group show very small differences for 1-phenyltetrazole compounds; they appear in the spectrum of 5EPT at nearly the same frequencies as in 5-methoxy-1-phenyltetrazole, ${ }^{29}$ 1-phenyltetrazole, ${ }^{32}$ 5-chloro1-phenyltetrazole, ${ }^{32}$ and 1-phenyltetrazolone. ${ }^{27}$ This result once again reinforces the idea that the presence of a second substituent at the tetrazole ring does not have a strong influence on the phenyl group, being also in agreement with the predicted small conjugation of the $\pi$ electron systems of phenyl and tetrazole rings in 5EPT (also in agreement with these results is the 
TABLE 1: Observed Frequencies $\left(\mathrm{cm}^{-1}\right)$ for 5-Ethoxy-1-phenyl-1H-tetrazole in an Argon Matrix ${ }^{a, b}$

\begin{tabular}{|c|c|c|c|c|}
\hline approximate description & calculated frequency & intensity & experimental frequency & intensity \\
\hline$v(\mathrm{C}-\mathrm{H}$ P-ring $1 / 2)$ & 3149.9 & 0.7 & 3203.6 & $\mathrm{w}$ \\
\hline$v(\mathrm{C}-\mathrm{H}$ P-ring $1 / 2)$ & 3144.6 & 0.3 & 3203.6 & $\mathrm{w}$ \\
\hline$v(\mathrm{C}-\mathrm{H}$ P-ring 3$)$ & 3123.2 & 15.1 & 3203.6 & $\mathrm{w}$ \\
\hline$v(\mathrm{C}-\mathrm{H}$ P-ring 4$)$ & 3111.6 & 11.1 & 3203.6 & $\mathrm{w}$ \\
\hline$v(\mathrm{C}-\mathrm{H}$ P-ring 5$)$ & 3101.7 & 0.0 & 3075.6 & $\mathrm{w}$ \\
\hline$v \mathrm{CH}_{3}$ as" & 3052.8 & 30.4 & 3075.6 & $\mathrm{w}$ \\
\hline$v \mathrm{CH}_{3}$ as' $^{\prime}$ & 3039.4 & 21.5 & 3075.6 & $\mathrm{w}$ \\
\hline$v \mathrm{CH}_{2}$ as & 3028.3 & 0.1 & 3003.9 & $\mathrm{sh}$ \\
\hline$\nu \mathrm{CH}_{2} \mathrm{~s}$ & 2992.1 & 14.3 & $3000.8 / 2985.2$ & $\mathrm{w} / \mathrm{w}$ \\
\hline$v \mathrm{CH}_{3} \mathrm{~s}$ & 2973.0 & 12.1 & 2967.4/2955.3/2939.8 & $w / w / w$ \\
\hline$v(\mathrm{C}-\mathrm{C}$ P-ring 2$)$ & 1605.5 & 24.0 & 1593.2 & $\mathrm{~m}$ \\
\hline$v(\mathrm{C}-\mathrm{C}$ P-ring 4$)$ & 1598.0 & 33.0 & 1590.0 & $\mathrm{~m}$ \\
\hline$v \mathrm{C}-\mathrm{O} / v \mathrm{~N}=\mathrm{C}$ & 1555.5 & 284.9 & $1567.2 / 1565.2 / 1552.5$ & $\mathrm{~S} / \mathrm{sh} / \mathrm{w}$ \\
\hline$\delta(\mathrm{C}-\mathrm{H}$ P-ring 2$)$ & 1499.2 & 115.2 & 1509.5 & $\mathrm{~S}$ \\
\hline$\delta \mathrm{CH}_{2}$ & 1484.2 & 26.0 & $1489.6 / 1481.3$ & $\mathrm{w} / \mathrm{w}$ \\
\hline$\delta \mathrm{CH}_{3}$ as $^{\prime}$ & 1466.6 & 3.4 & 1468.7 & $\mathrm{~m}$ \\
\hline$v(\mathrm{C}-\mathrm{H}$ P-ring 3$)$ & 1456.0 & 29.2 & 1462.3 & $\mathrm{~m}$ \\
\hline$\delta \mathrm{CH}_{3} \mathrm{as}^{\prime \prime}$ & 1452.8 & 9.0 & 1462.3 & $\mathrm{~m}$ \\
\hline$v \mathrm{C}-\mathrm{N}$ & 1441.8 & 102.0 & $1453.0 / 1447.5$ & $\mathrm{~m} / \mathrm{m}$ \\
\hline$\delta \mathrm{CH}_{3} \mathrm{~s}$ & 1392.6 & 69.9 & $1393.6 / 1388.5$ & $\mathrm{~S} / \mathrm{sh}$ \\
\hline$\omega \mathrm{CH}_{2}$ & 1363.1 & 52.4 & $1363.9 / 1360.6$ & $\mathrm{sh} / \mathrm{m}$ \\
\hline$v \mathrm{~N}=\mathrm{N}$ & 1342.2 & 35.9 & 1338.0 & $\mathrm{~m}$ \\
\hline$\delta(\mathrm{C}-\mathrm{H}$ P-ring 1$)$ & 1326.1 & 3.9 & 1321.8 & $\mathrm{w}$ \\
\hline$v(\mathrm{C}-\mathrm{C}$ P-ring 3$)$ & 1299.6 & 5.6 & 1306.9 & $\mathrm{~m}$ \\
\hline$v \mathrm{~N}=\mathrm{C} / v \mathrm{~N}-\mathrm{C}$ & 1287.3 & 37.4 & 1299.4/1297.6 & $\mathrm{m} / \mathrm{sh}$ \\
\hline $\mathrm{twCH}_{2}$ & 1271.8 & 1.2 & $1287.8 / 1285.5$ & $\mathrm{sh} / \mathrm{w}$ \\
\hline$\delta(\mathrm{C}-\mathrm{H}$ P-ring 4$)$ & 1176.9 & 1.8 & 1177.2 & $\mathrm{w}$ \\
\hline$\delta(\mathrm{C}-\mathrm{H}$ P-ring 5$)$ & 1158.9 & 0.3 & 1161.5 & $\mathrm{~W}$ \\
\hline$\gamma \mathrm{CH}_{3}{ }^{\prime \prime} / \gamma \mathrm{CH}_{2}$ & 1150.0 & 3.6 & 1161.5 & $\mathrm{w}$ \\
\hline$v \mathrm{~N}-\mathrm{N}$ & 1119.4 & 14.2 & $1135.7 / 1123.9$ & $\mathrm{w} / \mathrm{m}$ \\
\hline$\gamma \mathrm{CH}_{3}^{\prime}$ & 1103.0 & 39.1 & 1116.7 & $\mathrm{~m}$ \\
\hline$\delta(\mathrm{C}-\mathrm{C}$ P-ring 6$)$ & 1089.5 & 5.5 & 1105.2/1099.5/1093.0 & $\mathrm{sh} / \mathrm{w} / \mathrm{w}$ \\
\hline$\delta$ (T-ring 2) & 1064.4 & 85.8 & $1071.9 / 1070.1$ & $\mathrm{~m} / \mathrm{sh}$ \\
\hline$v(\mathrm{C}-\mathrm{C}$ P-ring 5$)$ & 1041.8 & 9.7 & $1050.5 / 1047.6$ & $\mathrm{sh} / \mathrm{w}$ \\
\hline$\nu \mathrm{C}-\mathrm{C} / v \mathrm{O}-\mathrm{C}$ & 1017.5 & 95.8 & $1030.0 / 1026.0$ & $\mathrm{~S} / \mathrm{sh}$ \\
\hline$v(\mathrm{C}-\mathrm{C}$ P-ring 1$) / \delta(\mathrm{P}$-ring 1$)$ & 1014.0 & 11.2 & 1014.2 & $\mathrm{sh}$ \\
\hline$v(\mathrm{C}-\mathrm{C}$ P-ring 1$) / \delta($ P-ring 1$)$ & 994.9 & 0.1 & 997.8 & $\mathrm{w}$ \\
\hline$\gamma(\mathrm{C}-\mathrm{H}$ P-ring 5) & 982.9 & 0.1 & 984.3 & $\mathrm{w}$ \\
\hline$\tau($ T-ring 2$) / v \mathrm{~N}-\mathrm{N}^{\prime}$ & 974.1 & 5.0 & $978.3 / 973.8$ & $\mathrm{w} / \mathrm{w}$ \\
\hline$\tau($ P-ring 3$) / \gamma(\mathrm{C}-\mathrm{H}$ P-ring 4$)$ & 966.1 & 0.1 & $978.3 / 973.8$ & $\mathrm{w} / \mathrm{w}$ \\
\hline$\gamma(\mathrm{C}-\mathrm{H}$ P-ring 3$)$ & 909.9 & 4.7 & $911.1 / 910.2 / 907.2$ & $\mathrm{w} / \mathrm{w} / \mathrm{sh}$ \\
\hline$\nu \mathrm{O}-\mathrm{C}$ & 889.6 & 32.8 & 902.9/901.0/900.0/886.3/884.9 & $\mathrm{w} / \mathrm{w} / \mathrm{w} / \mathrm{w} / \mathrm{w}$ \\
\hline$\gamma(\mathrm{C}-\mathrm{H}$ P-ring 2$)$ & 830.5 & 0.1 & 829.7 & w \\
\hline$\gamma \mathrm{CH}_{3}^{\prime \prime} / \gamma \mathrm{CH}_{2}$ & 798.5 & 0.6 & 809.9 & $\mathrm{w}$ \\
\hline$\delta($ T-ring 1$) / \nu \mathrm{C}-\mathrm{O} / \nu(\mathrm{C}-\mathrm{C}$ P-ring 1$)$ & 767.2 & 1.5 & $776.6 / 764.5$ & $\mathrm{w} / \mathrm{sh}$ \\
\hline$\gamma(\mathrm{C}-\mathrm{H}$ P-ring 1$)$ & 754.1 & 59.2 & $757.0 / 755.4$ & $\mathrm{~m} / \mathrm{m}$ \\
\hline$\tau(\mathrm{T}$-ring 2$) / \gamma \mathrm{CO}$ & 717.9 & 4.4 & $735.4 / 730.5$ & $\mathrm{w} / \mathrm{w}$ \\
\hline$\tau($ P-ring 1$) / \tau($ T-ring 1$)$ & 690.0 & 13.5 & $697.2 / 694.6$ & $\mathrm{w} / \mathrm{w}$ \\
\hline$\delta($ P-ring 3$)$ & 681.5 & 15.0 & 685.7 & $\mathrm{~m}$ \\
\hline$\tau($ T-ring 1$)$ & 679.1 & 15.7 & $684.0 / 682.1 / 670.9$ & $\mathrm{~m} / \mathrm{sh} / \mathrm{w}$ \\
\hline$\delta($ P-ring 2$)$ & 616.3 & 0.2 & 617.2 & $\mathrm{w}$ \\
\hline$\delta \mathrm{CO} / \delta \mathrm{NC}$ & 563.4 & 4.2 & 568.2 & $\mathrm{w}$ \\
\hline$\gamma \mathrm{NC}$ & 498.0 & 11.2 & 506.8 & $\mathrm{w}$ \\
\hline$\gamma(\mathrm{C}-\mathrm{H}$ P-ring 4$) / \tau($ P-ring 3$)$ & 405.3 & 0.2 & 506.8 & $\mathrm{w}$ \\
\hline$\delta \mathrm{OCC} / \delta \mathrm{CN}$ & 385.2 & 2.3 & 506.8 & $\mathrm{w}$ \\
\hline$\gamma \mathrm{CO}$ & 353.5 & 4.2 & 506.8 & $\mathrm{w}$ \\
\hline$\delta \mathrm{OCC}$ & 325.0 & 5.6 & 506.8 & $\mathrm{~W}$ \\
\hline$\delta \mathrm{CN} / \tau($ T-ring 2$)$ & 298.5 & 2.3 & 506.8 & $\mathrm{w}$ \\
\hline$\tau($ P-ring 2) & 258.2 & 0.7 & 506.8 & $\mathrm{w}$ \\
\hline$\tau \mathrm{CH}_{3}$ & 242.5 & 0.1 & n.i. & n.i. \\
\hline$\delta \mathrm{C}-\mathrm{O}-\mathrm{CH}_{3} / \delta \mathrm{CN}$ & 176.1 & 1.8 & n.i. & n.i. \\
\hline$\gamma \mathrm{CN} / \tau \mathrm{C}-\mathrm{O}$ & 114.2 & 2.0 & n.i. & n.i. \\
\hline$\tau \mathrm{C}-\mathrm{O}$ & 88.0 & 0.9 & n.i. & n.i. \\
\hline$\delta$ (P-ring 1$) / \delta \mathrm{NC} / \tau \mathrm{C}-\mathrm{O}$ & 76.2 & 0.4 & n.i. & n.i. \\
\hline$\tau \mathrm{O}-\mathrm{C}$ & 58.1 & 0.9 & n.i. & n.i. \\
\hline$\tau \mathrm{C}-\mathrm{N}$ & 29.1 & 0.8 & n.i. & n.i. \\
\hline
\end{tabular}

${ }^{a}$ DFT(B3LYP)/6-311++G(d,p) calculated frequencies $\left(\mathrm{cm}^{-1}\right.$; scaled by 0.978$)$ and intensities $\left(\mathrm{km} \mathrm{mol}^{-1}\right)$ are given for comparison. ${ }^{b}$ Results of calculations presented in this table concern the $\mathbf{T}$ conformer (see text for discussion). $\nu$, bond stretching; $\delta$, bending; $\gamma$, rocking; $\tau$, torsion; $\mathrm{s}$, symmetric; as, antisymmetric; P-ring, phenyl ring; T-ring, tetrazole ring. See Table S2 (Supporting Information) for definition of internal coordinates. S, strong; m, medium; w, weak, sh, shoulder; n.i., not investigated.

fact that the optimized structures of the various 1-phenyltetrazole compounds already studied, ${ }^{27,29,31,32}$ including 5EPT, do not show any substantial differences in the geometry of the phenyl group). 


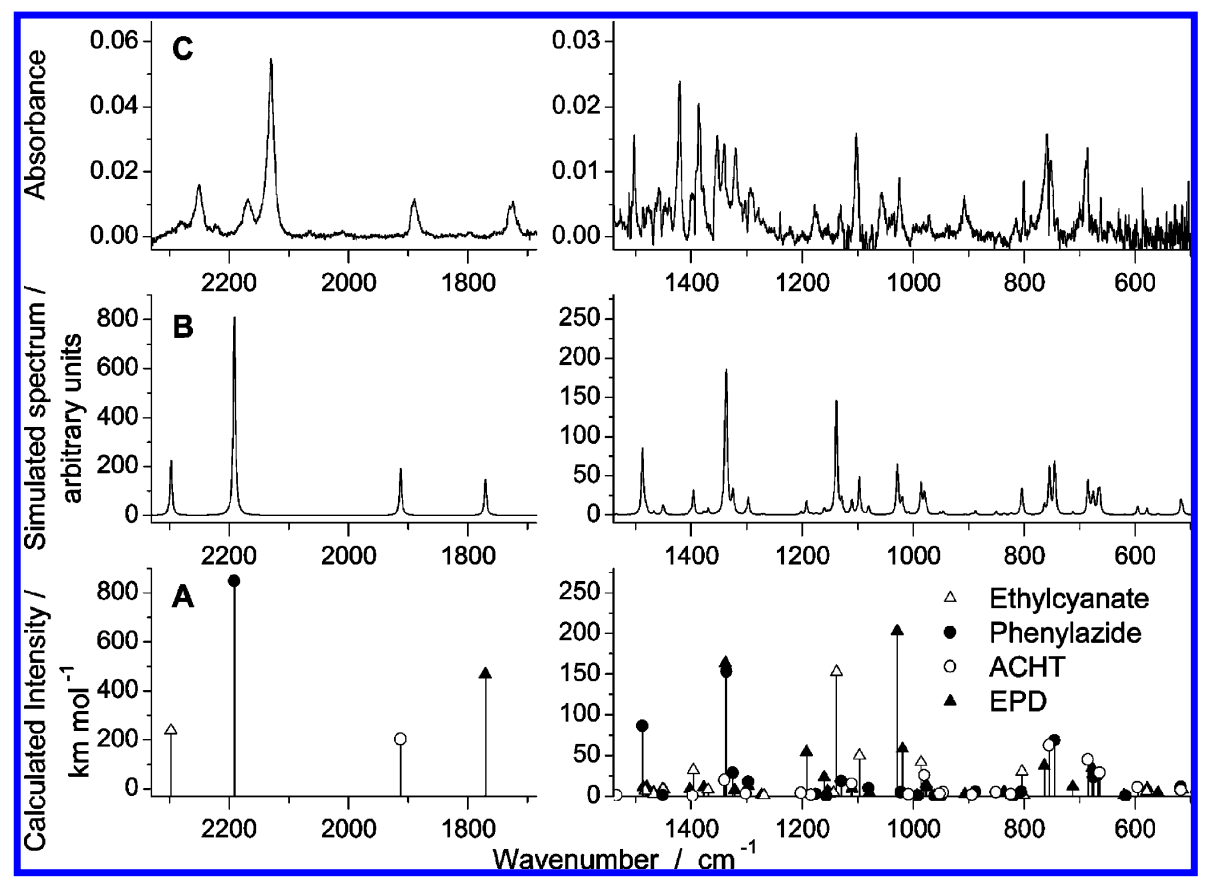

Figure 4. (A) DFT(B3LYP)/6-311++G(d,p) calculated spectra of the possible photoproducts: $\triangle$, ethylcyanate (the most stable conformer EC-A); - phenylazide; O, ACHT; $\mathbf{\Lambda}$, EPD (most stable conformer T-A). The calculated wavenumbers were scaled with a uniform factor of 0.978. (B) Simulated infrared spectrum for the mixture of photoproducts. It was created using Lorentzian functions centered at the calculated (scaled) frequencies [shown in (A)] and with bandwidths at half-height equal to $4 \mathrm{~cm}^{-1}$. Note that the calculated intensities in the sum spectrum relate in the proportion 1:1:1:0.33, where 0.33 refers to EPD and unities refer to ethylcyanate, phenylazide, and ACHT. (C) Extracted spectrum of the photoproducts formed after $60 \mathrm{~min}$ of UV irradiation $(\lambda>235 \mathrm{~nm})$ of 5EPT trapped in an Ar matrix. The extracted spectrum was obtained by subtraction of the scaled spectrum of nonirradiated matrix from the spectrum of irradiated sample. The scaling factor was chosen so that the absorptions due to the originally deposited compound (5EPT) were nullified.

As could be expected, in contrast to the phenyl vibrations, the tetrazole ring vibrations are strongly affected by the substituent at the $\mathrm{C}_{(5)}$-position and differ considerably among different compounds. The most intense bands in the IR spectrum of 5EPT are associated with modes originated in this group, as well as in the ethoxy group, corresponding to the $v \mathrm{C}-\mathrm{O} / v \mathrm{~N}=\mathrm{C}, \nu \mathrm{C}-\mathrm{N}, v \mathrm{~N}=\mathrm{C} / v \mathrm{~N}-\mathrm{C}, v \mathrm{~N}-\mathrm{N}, \delta(\mathrm{T}$-ring 2), $\nu \mathrm{C}-\mathrm{C} / \nu \mathrm{O}-\mathrm{C}, \delta \mathrm{CH}_{3}$ symmetric, and $\omega \mathrm{CH}_{2}$ vibrational modes (see Table 1 and also Table S2 for definition of coordinates). The $v \mathrm{C}-\mathrm{O} / v \mathrm{~N}=\mathrm{C}$ vibrational mode, localized within both the $\mathrm{C}_{(5)}-\mathrm{O}_{(17)}$ and $\mathrm{C}_{(5)}-\mathrm{N}_{(4)}$ bonds, gives rise to the most intense band of the spectrum and occurs as a triplet at 1567.2/1565.2/ $1552.5 \mathrm{~cm}^{-1}$ (see Figure 3 and Table 1). In 5-methoxy-1phenyltetrazole ${ }^{29}$ the equivalent vibration absorbs as a site-split doublet at 1572.3 and $1571.3 \mathrm{~cm}^{-1}$. The $v \mathrm{C}-\mathrm{N}$ vibration (associated with the $\mathrm{C}_{(5)}-\mathrm{N}_{(1)}$ bond) gives rise to a doublet at $1453.0 / 1447.5 \mathrm{~cm}^{-1}$, while that ascribable to the $v \mathrm{~N}-\mathrm{C}$ coordinate (associated with the $\mathrm{N}_{(1)}-\mathrm{C}_{(6)}$ inter-ring bond) is observed as a doublet at 1299.4/1297.6 $\mathrm{cm}^{-1}$ (Table 1). According to the results of normal-mode analysis (see Table $\mathrm{S} 3$ ), these coordinates are somewhat coupled with the $v \mathrm{~N}=\mathrm{C}$ coordinate (especially $v \mathrm{~N}-\mathrm{C}$ ), which may justify their relatively high frequency. The $v \mathrm{~N}-\mathrm{N}$ vibrational mode, mainly localized in the $\mathrm{N}_{(3)}-\mathrm{N}_{(4)}$ bond, is observed as a doublet at 1135.7/1123.9 $\mathrm{cm}^{-1}$ and does also correspond to a considerably delocalized mode (see Table S3). Another intense band in the spectrum of 5EPT is observed at $1071.9 / 1070.1 \mathrm{~cm}^{-1}$, corresponding to the tetrazole ring $\delta$ (T-ring 2 ) vibration. In 5-methoxy-1-phenyltetrazole, ${ }^{29} 1$-phenyltetrazole, and 5-chloro-1-phenyltetrazole, ${ }^{32}$ the equivalent vibrations appear at 1101.3/1096.9, 1089.5/1085.4, and $1109.1 / 1102.4 \mathrm{~cm}^{-1}$, respectively, and are also comparable in intensity to the observed band of 5EPT. The $\delta \mathrm{CH}_{3}$ symmetric and $\omega \mathrm{CH}_{2}$ deformational modes of the ethyl group give rise also to relatively intense IR bands and appear as doublets at
1393.6/1388.5 and 1363.9/1360.6 $\mathrm{cm}^{-1}$, respectively. Finally, the $v \mathrm{C}-\mathrm{C} / v \mathrm{O}-\mathrm{C}$ mixed stretching mode is the last vibration among those giving rise to intense bands that were mentioned above. It is observed at $1030.0 / 1026.0 \mathrm{~cm}^{-1}$, i.e., within the characteristic frequency range for this mode in methyl esters and methyl ethers (around 1050-950 $\mathrm{cm}^{-1}$ ). ${ }^{12}$

The remaining intense bands in the IR spectrum of 5EPT belong to the phenyl moiety, being observed at $1509.5 \mathrm{~cm}^{-1}$ $\delta\left(\mathrm{C}-\mathrm{H}\right.$ P-ring 2), $1462.3 \mathrm{~cm}^{-1} v(\mathrm{C}-\mathrm{H}$ P-ring 3$)$ and $757.0 /$ $755.4 \mathrm{~cm}^{-1} \gamma(\mathrm{C}-\mathrm{H}$ P-ring 1$)$ (see Table 1$)$.

In Situ UV Irradiation Experiments $(\lambda>235$ nm). To study the photochemistry of the matrix-isolated 5EPT, in situ UV-irradiation $(\lambda>235 \mathrm{~nm})$ experiments were carried out. The resulting photochemical processes were followed by IR spectroscopy. The interpretation of the experimental data was supported by extensive DFT calculations of the possible photoproducts and, whenever available, taking into consideration previously reported spectroscopic data obtained for putative photoproducts.

Upon irradiation, the bands due to 5EPT decrease in intensity, indicating that the compound is being transformed in other species, while new bands appear in the spectrum. The changes are particularly evident in the $2300-1700 \mathrm{~cm}^{-1}$ spectral region, which is shown in Figure 4C (spectrum of the photoproducts). The photochemically induced opening of the tetrazole ring has been found to be a common process. ${ }^{22-24,64-69}$ As mentioned before, unsubstituted tetrazole easily eliminates molecular nitrogen, leading to production of nitrilimine, which then undergoes secondary photoreactions, such as isomerization to carbodiimide, cyanamide, or a hydrogen cyanide/nitrene complex..$^{23}$ The proposed reaction pathways resulting from irradiation of 5EPT are schematically shown in Scheme 1, and the complete list of bands due to the products of photolysis is presented in Tables 2 and 3. 
TABLE 2: Experimental and Calculated [B3LYP/6-311++G(d,p); Scaled by 0.978] Vibrational Frequencies $\left(\mathrm{cm}^{-1}\right)$ and Calculated IR Intensities $\left(\mathrm{km} \mathrm{mol}^{-1}\right)$ for Ethylcyanate, Phenylazide and 1-aza-1,2,4,6-cycloheptatetraene (ACHT) (Photoproducts Formed by Irradiation of 5-Ethoxy-1-phenyl-1H-tetrazole in Solid Argon ${ }^{a}$ )

\begin{tabular}{|c|c|c|c|c|c|}
\hline \multirow[b]{2}{*}{ approximate description $^{b}$} & \multirow[b]{2}{*}{ sym } & \multicolumn{2}{|c|}{ calculated } & \multirow[b]{2}{*}{ observed frequency $\left(\mathrm{cm}^{-1}\right)$} & \multirow[b]{2}{*}{ literature frequency $\left(\mathrm{cm}^{-1}\right)$} \\
\hline & & frequency $\left(\mathrm{cm}^{-1}\right)$ & intensity $\left(\mathrm{km} \mathrm{mol}^{-1}\right)$ & & \\
\hline ethylcyanate & $C_{s}$ & & & & (gas phase) $^{81}$ \\
\hline$v \mathrm{OCN}$ as & $\mathrm{A}^{\prime}$ & 2297.2 & 237.9 & $2251.2 / 2245.3$ & $2262 / 2255 / 2248$ \\
\hline$\delta \mathrm{CH}_{2}$ & $\mathrm{~A}^{\prime}$ & 1482.5 & 6.8 & 1480.0 & $\{1480$ \\
\hline$\delta \mathrm{CH}_{3}$ as' $^{\prime}$ & $A^{\prime}$ & 1467.2 & 2.8 & 1474.7 & \{ \\
\hline$\delta \mathrm{CH}_{3} \mathrm{as}^{\prime \prime}$ & $\mathrm{A}^{\prime \prime}$ & 1450.1 & 8.6 & 1439.6 & 1454 \\
\hline$\delta \mathrm{CH}_{3} \mathrm{~s}$ & $\mathrm{~A}^{\prime}$ & 1395.8 & 32.1 & $1386.2 / 1384.0$ & 1401 \\
\hline$\omega \mathrm{CH}_{2}$ & $\mathrm{~A}^{\prime}$ & 1369.3 & 8.1 & 1379.6 & 1377 \\
\hline $\mathrm{twCH}_{2}$ & $A^{\prime \prime}$ & 1268.8 & 0.8 & 1287.0 & 1290 \\
\hline$\gamma \mathrm{CH}_{2}$ & $A^{\prime \prime}$ & 1143.3 & 4.6 & 1136.6 & 1136 \\
\hline$v \mathrm{OCN} s$ & $\mathrm{~A}^{\prime}$ & 1138.2 & 152.6 & 1133.8 & 1113 \\
\hline$\gamma \mathrm{CH}_{3}^{\prime}$ & $\mathrm{A}^{\prime}$ & 1096.8 & 49.9 & 1085.0 & 1106 \\
\hline$v \mathrm{CC}$ & $\mathrm{A}^{\prime}$ & 985.8 & 41.5 & $997.5 / 992.0$ & 1008 \\
\hline$\nu \mathrm{C}-\mathrm{O}$ & $A^{\prime}$ & 804.0 & 30.2 & 805.6 & $\int 825$ \\
\hline$\gamma \mathrm{CH}_{3}{ }^{\prime}$ & $\mathrm{A}^{\prime \prime}$ & 801.2 & 1.3 & 800.8 & $\{814$ \\
\hline$\delta \mathrm{OCN}$ & $\mathrm{A}^{\prime}$ & 579.3 & 5.9 & 596.8 & \\
\hline phenylazide & $C_{s}$ & & & & $\left(\mathrm{~N}_{2} \text { matrix }\right)^{82}$ \\
\hline$v \mathrm{~N}=\mathrm{N}=\mathrm{N}$ as & $A^{\prime}$ & 2191.4 & 843.5 & $2168.7 / 2130.3$ & $\begin{array}{l}2165 / 2157 / 2137 / 2128^{c} \\
2112 / 2102 / 2087\end{array}$ \\
\hline$v(\mathrm{C}-\mathrm{C}$ ring 2$)$ & $\mathrm{A}^{\prime}$ & 1600.5 & 59.2 & 1621.1 & 1598 \\
\hline$v(\mathrm{C}-\mathrm{C}$ ring 4$)$ & $\mathrm{A}^{\prime}$ & 1585.3 & 6.4 & 1579.7 & $1589 / 1585$ \\
\hline$\delta(\mathrm{C}-\mathrm{H}$ ring 2$)$ & $\mathrm{A}^{\prime}$ & 1487.7 & 86.3 & 1502.3 & $1496 / 1491$ \\
\hline$\nu \mathrm{N}=\mathrm{N}=\mathrm{N} \mathrm{s}$ & $\mathrm{A}^{\prime}$ & 1336.4 & 151.2 & $1354.3 / 1352.7 / 1361.5$ & 1398 \\
\hline$\delta(\mathrm{C}-\mathrm{H}$ ring 1$)$ & $\mathrm{A}^{\prime}$ & 1325.0 & 29.8 & 1318.7 & 1337 \\
\hline$v(\mathrm{C}-\mathrm{C}$ ring 3$)$ & $\mathrm{A}^{\prime}$ & 1296.8 & 18.2 & 1293.3 & $1305 / 1298$ \\
\hline$\delta(\mathrm{C}-\mathrm{H}$ ring 4$)$ & $\mathrm{A}^{\prime}$ & 1174.6 & 2.4 & $1174.4(?)$ & 1176 \\
\hline$v \mathrm{~N}-\mathrm{C}$ & $\mathrm{A}^{\prime}$ & 1128.9 & 18.3 & 1125.2 & $1136 / 1131$ \\
\hline$v(\mathrm{C}-\mathrm{C}$ ring 5$)$ & $\mathrm{A}^{\prime}$ & 1022.0 & 4.4 & 1025.2 & 1026 \\
\hline$\gamma(\mathrm{C}-\mathrm{H}$ ring 3$)$ & $\mathrm{A}^{\prime \prime}$ & 887.7 & 5.2 & 886.5 & 896 \\
\hline$\delta \mathrm{CNN}$ & $\mathrm{A}^{\prime}$ & 805.5 & 5.3 & 814.0 & 810 \\
\hline$\gamma(\mathrm{C}-\mathrm{H}$ ring 1$)$ & $A^{\prime \prime}$ & 744.9 & 68.7 & 740.4 & 751 \\
\hline$\tau($ ring 1$)$ & $\mathrm{A}^{\prime \prime}$ & 675.2 & 23.2 & 663.6 & 687 \\
\hline$\delta$ NNN & $\mathrm{A}^{\prime}$ & 666.9 & 25.1 & 662.0 & 670 \\
\hline ACHT & $\mathrm{C} 1$ & & & & $(\text { Ar matrix })^{83}$ \\
\hline$\nu \mathrm{C}=\mathrm{C}=\mathrm{N}$ as & & 1913.1 & 202.2 & 1891.5 & 1895 \\
\hline$\delta(\mathrm{C}-\mathrm{H} 1)$ & & 1201.8 & 3.9 & 1222.3 & \\
\hline$\delta(\mathrm{C}-\mathrm{H} 2)$ & & 1110.9 & 15.2 & $1104.3 / 1102.3$ & 1111 \\
\hline$v \mathrm{~N}-\mathrm{C}$ & & 979.7 & 25.6 & 970.4 & 980 \\
\hline$\gamma(\mathrm{C}-\mathrm{H} 1)$ & & 951.4 & 3.0 & 939.4 & $\{940$ \\
\hline$\gamma(\mathrm{C}-\mathrm{H} 2)$ & & 945.7 & 4.5 & 935.4 & $\left\{\begin{array}{l}200 \\
0\end{array}\right.$ \\
\hline$\gamma(\mathrm{C}-\mathrm{H} 3)$ & & 754.3 & 62.3 & 748.0 & 748 \\
\hline$\delta \mathrm{CCN}$ & & 685.0 & 45.5 & 689.7 & 683 \\
\hline$\tau($ ring 1$)$ & & 663.8 & 28.2 & 652.4 & $658 / 650$ \\
\hline$\gamma \mathrm{CCN}$ & & 595.5 & 10.9 & 586.4 & 580 \\
\hline
\end{tabular}

${ }^{a}$ Complete calculated spectra are presented in Tables S6-S9 (Supporting Information). ${ }^{b} v$ : stretching; $\delta$ : bending; $\gamma$ : rocking; $\tau$ : torsion; tw: twisting; ring modes were given the names in consonance with those used for 5EPT. ${ }^{c}$ Shoulder.

The observed photochemistry of 5EPT shows two major reaction pathways: (1) cleavage of the tetrazole ring through the $\mathrm{C}_{(5)}-\mathrm{N}_{(1)}$ and $\mathrm{N}_{(3)}-\mathrm{N}_{(4)}$ bonds, with production of phenylazide and ethylcyanate as primary photoproducts (phenylazide can then undergo further reactions to give 1-aza-1,2,4,6cycloheptatetraene, ACHT), and (2) cleavage of the $\mathrm{N}_{(1)}-\mathrm{N}_{(2)}$ and $\mathrm{N}_{(3)}-\mathrm{N}_{(4)}$ bonds, with molecular nitrogen elimination, leading to formation of the antiaromatic 3-ethoxy-1-phenyl-1Hdiazirene (EPD). Both observed photoprocesses imply cleavage of the $\mathrm{N}_{(3)}-\mathrm{N}_{(4)}$ bond. The first one also implies disruption of the $\mathrm{C}_{(5)}-\mathrm{N}_{(1)}$ bond, while the second one requires cleavage of the $\mathrm{N}_{(1)}-\mathrm{N}_{(2)}$ bond. These are the three formally single bonds in the tetrazole ring, with calculated lengths longer than 135.7 pm (Table S1, Supporting Information). The $\mathrm{N}_{(2)}-\mathrm{N}_{(3)}$ and $\mathrm{C}_{(5)}-$ $\mathrm{N}_{(4)}$ bonds are considerably shorter (128.0 and $131.4 \mathrm{pm}$, respectively, as calculated at the DFT(B3LYP)/6-311++G(d,p) level of theory), and represent the two double bonds of the tetrazolic system. Thus, the bonds that undergo cleavage in the photoreactions correspond to the tetrazole ring's weakest bonds.
As could be expected, and similar to what was previously observed for the closely related molecule 5-methoxytetrazole, ${ }^{29}$ the first observed photoprocess is clearly the preferred reaction channel in 5EPT, as can be noticed by comparing the relative intensities of the characteristic bands due to the different photoproducts appearing in the $2300-1700 \mathrm{~cm}^{-1}$ spectral range.

All strong and medium intensity bands predicted for the two major products formed in pathway 1 (phenylazide and ethylcyanate) could be observed in the spectra of the irradiated matrix (see Figure 4 and Table 2).

Covalent cyanates $(\mathrm{R}-\mathrm{O}-\mathrm{C} \equiv \mathrm{N})$ are in general unstable compounds and isomerize into their thermodynamically more stable isocyanate derivatives. The cyanate structure is stable only in special cases, e.g., if the substituent, $\mathrm{R}$, is an aryl group, ${ }^{70,71}$ or if the substituent is bulky, preventing the isomerization for steric reasons. ${ }^{72,73}$ Ethylcyanate, $\mathrm{CH}_{3} \mathrm{CH}_{2} \mathrm{OCN}$, is not an exception. It isomerizes readily at room or higher temperatures, ${ }^{74}$ and the process is believed to be autocatalyzed. ${ }^{71}$ Because of its instability, ethylcyanate can only be stored at low temperature 
TABLE 3: Experimental and Calculated [B3LYP/ 6-311++G9(d,p); Scaled by 0.978] Vibrational Frequencies $\left(\mathrm{cm}^{-1}\right)$ and Calculated IR Intensities $\left(\mathrm{km} \mathrm{mol}^{-1}\right)$ for 3-Ethoxy-1-phenyl-1H-diazirene (EPD) (Photoproduct Formed by Irradiation of 5-Ethoxy-1-phenyl-1H-tetrazole in Solid Argon ${ }^{a}$ )

\begin{tabular}{|c|c|c|c|}
\hline \multirow[b]{2}{*}{$\begin{array}{l}\text { approximate } \\
\text { description }^{b}\end{array}$} & \multicolumn{2}{|c|}{ calculated } & \multirow{2}{*}{$\begin{array}{c}\text { observed } \\
\text { frequency } \\
\left(\mathrm{cm}^{-1}\right)\end{array}$} \\
\hline & $\begin{array}{c}\text { frequency } \\
\left(\mathrm{cm}^{-1}\right)\end{array}$ & $\begin{array}{c}\text { intensity } \\
\left(\mathrm{km} \mathrm{mol}^{-1}\right)\end{array}$ & \\
\hline \multicolumn{4}{|l|}{ EPD } \\
\hline$\nu \mathrm{C}=\mathrm{N}$ & 1770.4 & 468.2 & 1724.5 \\
\hline$\delta(\mathrm{C}-\mathrm{H} \operatorname{ring} 2)$ & 1594.1 & 0.5 & 1572.7 \\
\hline$\delta(\mathrm{C}-\mathrm{H} \operatorname{ring} 1)$ & 1579.0 & 0.5 & 1572.7 \\
\hline$\delta \mathrm{CH}_{2}$ & 1486.0 & 10.9 & $1480.0^{c}$ \\
\hline$\delta(\mathrm{C}-\mathrm{H}$ ring 4$)$ & 1479.7 & 11.6 & 1477.5 \\
\hline$\delta \mathrm{CH}_{3}$ as $^{\prime}$ & 1467.2 & 4.9 & $1474.7^{c}$ \\
\hline$\gamma \mathrm{CH}_{3}^{\prime}$ & 1451.9 & 8.2 & $1445.6 / 1439.6$ \\
\hline$\delta(\mathrm{C}-\mathrm{H}$ ring 5$)$ & 1448.6 & 7.8 & $1425.6 / 1420.2$ \\
\hline$\omega \mathrm{CH}_{2}$ & 1401.9 & 8.5 & $1348.8 / 1346.9$ \\
\hline$\delta \mathrm{CH}_{3} \mathrm{~s}$ & 1377.1 & 10.8 & 1388.1 \\
\hline$\delta \mathrm{CN}$ & 1338.0 & 163.6 & 1324.2 \\
\hline$\delta(\mathrm{C}-\mathrm{H}$ ring 2$)$ & 1321.7 & 7.7 & 1322.0 \\
\hline$\delta(\mathrm{C}-\mathrm{H}$ ring 1$)$ & 1296.9 & 12.2 & $1293.3^{d}$ \\
\hline $\mathrm{twCH}_{2}$ & 1273.3 & 1.8 & 1278.8 \\
\hline$\delta(\mathrm{C}-\mathrm{H}$ ring 4$)$ & 1192.0 & 54.2 & 1177.4 \\
\hline$\delta(\mathrm{C}-\mathrm{H}$ ring 5$)$ & 1160.2 & 23.4 & $1174.4^{d}$ \\
\hline$v(\mathrm{C}-\mathrm{C}$ ring 5$)$ & 1154.1 & 6.8 & 1133.6 \\
\hline $\mathrm{twCH}_{2}$ & 1150.6 & 3.2 & 1133.6 \\
\hline$\gamma \mathrm{CH}_{3}^{\prime}$ & 1110.2 & 9.5 & 1111.2 \\
\hline$v(\mathrm{C}-\mathrm{C}$ ring 5$)$ & 1079.0 & 4.6 & 1082.8 \\
\hline$\nu \mathrm{O}-\mathrm{C}\left(\mathrm{H}_{2}\right)$ & 1028.3 & 203.2 & 1055.9 \\
\hline$\gamma(\mathrm{C}-\mathrm{H}$ ring 3$)$ & 1019.1 & 58.1 & $1025.2^{d}$ \\
\hline$v(\mathrm{C}-\mathrm{C}$ ring 5$)$ & 992.8 & 0.7 & n.o..$^{e}$ \\
\hline$\gamma(\mathrm{C}-\mathrm{H}$ ring 5$)$ & 976.5 & 14.6 & 970.4 \\
\hline$\gamma(\mathrm{C}-\mathrm{H}$ ring 1$)$ & 976.0 & 11.1 & 970.4 \\
\hline$\gamma(\mathrm{C}-\mathrm{H}$ ring 2$)$ & 960.1 & 0.5 & 959.8 \\
\hline$\gamma(\mathrm{C}-\mathrm{H}$ ring 4$)$ & 906.9 & 2.5 & $886.5^{d}$ \\
\hline$v \mathrm{C}-\mathrm{O}$ & 835.9 & 5.7 & 833.2 \\
\hline$\gamma(\mathrm{C}-\mathrm{H}$ ring 1$)$ & 822.1 & 1.1 & 821.0 \\
\hline$\gamma(\mathrm{NN}(\mathrm{C}) \mathrm{O})^{f}$ & 806.0 & 4.8 & $805.6^{c}$ \\
\hline$\gamma \mathrm{CH}_{3}^{\prime}$ & 800.5 & 0.7 & $800.8^{c}$ \\
\hline$\tau($ ring 1$)$ & 763.8 & 37.7 & $788.8 / 784.7$ \\
\hline$\tau($ ring 2$)$ & 712.2 & 11.5 & 735.6 \\
\hline$\tau(\operatorname{ring} 3)$ & 677.7 & 35.2 & 682.2 \\
\hline
\end{tabular}

${ }^{a}$ Complete calculated spectra are presented in Tables S10-S12 (Supporting Information). ${ }^{b} v$, stretching; $\delta$, bending; $\gamma$, rocking; $\tau$, torsion; tw, twisting. Ring modes were given names in consonance with those used for 5EPT. ${ }^{c}$ Overlapped with a band of ethylcyanate. ${ }^{d}$ Overlapped with a band of phenylazide. ${ }^{e}$ n.o., not observed. ${ }^{f} \mathrm{C}$ out of the $\mathrm{N}-\mathrm{N}-(\mathrm{C})-\mathrm{O}$ plane bending vibration.

and its application in chemical reactions requires its generation in situ prior to use. ${ }^{75-77}$ For the same reason, little is known experimentally about ethylcyanate structure and spectroscopy. The $\mathrm{IR}^{78,79}$ and $\mathrm{NMR}^{78}$ spectra of the compound were recorded in cold $\mathrm{CCl}_{4}$ solution. Gas-phase investigations on this substance include only early mass ${ }^{80}$ and microwave ${ }^{81}$ spectroscopic studies. More recently, gaseous ethylcyanate has been generated from the gas/solid reaction of $O$-ethyl thiocarbamate with mercury oxide, and characterized in the gas phase by infrared spectroscopy. ${ }^{82}$

In the present study, all bands previously observed in the gas-phase spectrum of ethylcyanate ${ }^{82}$ could be identified in the spectra of the irradiated matrix (Table 2), unequivocally testifying the presence there of this species. Very interestingly, no evidence of isomerization of ethylcyanate to ethylisocyanate was found, indicating that under the experimental conditions used ethylcyanate is stable in relation to the isomerization to the isocyanate.

It is worth noticing that ethylcyanate has one intramolecular degree of freedom, corresponding to internal rotation around
SCHEME 1: Proposed Pathways Resulting from Irradiation of 5-Ethoxy-1-phenyl-1H-tetrazole in an Argon Matrix through the Outer $\mathrm{KBr}$ Window of the Cryostat $(\lambda>235 \mathrm{~nm})$

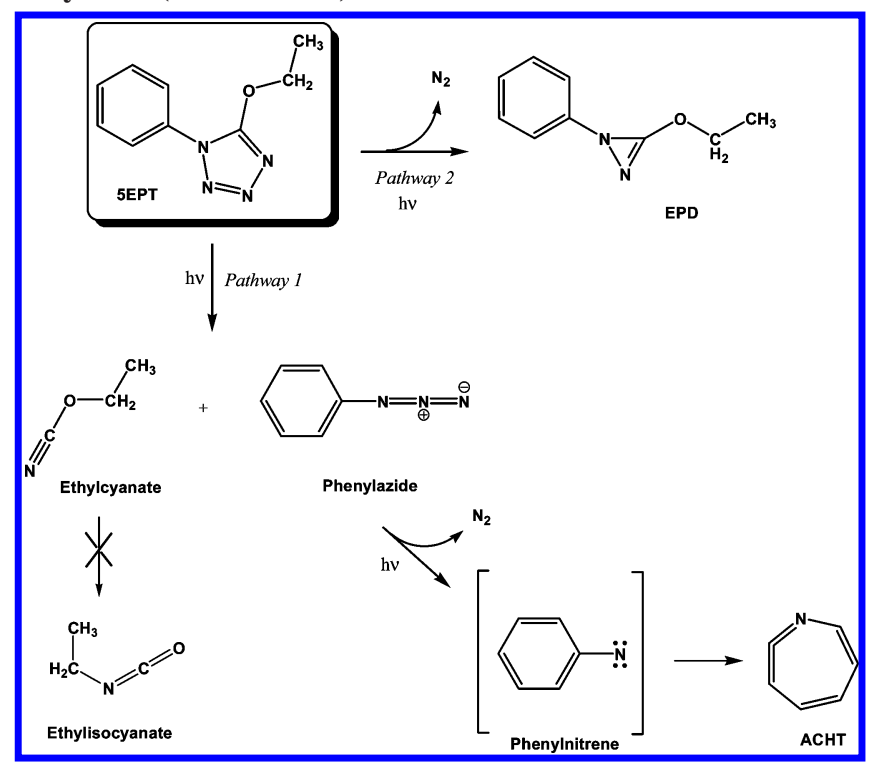

the $-\mathrm{C}_{(4)}-\mathrm{O}-$ axis (see Table S6, Supporting Information), which may result in the existence of different conformers. The potential energy profile for internal rotation around the $-\mathrm{C}_{(4)}-\mathrm{O}-$ bond in ethylcyanate (see Figure 5) was calculated by incrementing the value of the $\mathrm{C}-\mathrm{C}-\mathrm{O}-\mathrm{C}$ dihedral angle and fully optimizing all other geometric parameters. This relaxed potential energy scan confirmed the existence of three local minima, which are associated with conformers $\mathbf{T}, \mathbf{G}$, and $\mathbf{G}^{\prime}$ (structures $\mathbf{G}$ and $\mathbf{G}^{\prime}$ are mirror images). The energy barrier separating the $\mathbf{G}$ and $\mathbf{G}^{\prime}$ forms from the most stable form $\mathbf{T}$ is very low, amounting to less than $4 \mathrm{~kJ} \mathrm{~mol}^{-1}$. The optimized geometries of these conformers were obtained at the DFT(B3LYP)/6-311++G(d,p) level of theory and are depicted graphically as Supporting Information in Tables S6 and S7. Similarly to the matrix-isolated 5EPT, the photochemically produced ethylcyanate can also be expected to undergo conformational cooling, since the barrier to intramolecular rotation remains low in this species. This justifies the excellent correspondence between the observed features ascribable to ethylcyanate and the theoretical spectrum of the $\mathbf{T}$ conformer.

In pathway 1, phenylazide is produced together with ethylcyanate (Scheme 1). The photogeneration of phenylazide in argon matrix has been reported previously, and formation of 1-aza-1,2,4,6-cycloheptatetraene (ACHT) unequivocally demonstrated. ${ }^{27}$ The vibrational spectra of matrix-isolated phenylazide $^{83}$ and of $\mathrm{ACHT}^{84}$ are thus well-known, and their identification could be made here without any difficulty (see Table 2). Under the experimental conditions used, phenylazide reacts with relatively low efficiency, in particular when compared to the reactions undergone by the tetrazole compounds. The intermediate for this reaction is, with all probability, the singlet phenylnitrene, which has been found ${ }^{85}$ to easily undergo ring expansion to ACHT (the calculated ground-state energies for these two species favor the latter compound by ca. $80 \mathrm{~kJ}$ $\mathrm{mol}^{-1}$ ).

Characteristic bands of $\mathrm{ACHT}^{27}$ were clearly identified in the spectra of the irradiated matrix. Particularly evident is the band mark associated with the intense antisymmetric stretching vibration of the ketenimine moiety $(\nu \mathrm{C}=\mathrm{C}=\mathrm{N}$ as $)$ of ACHT, observed at $1891.5 \mathrm{~cm}^{-1}$ (Figure 4). Other bands previously 


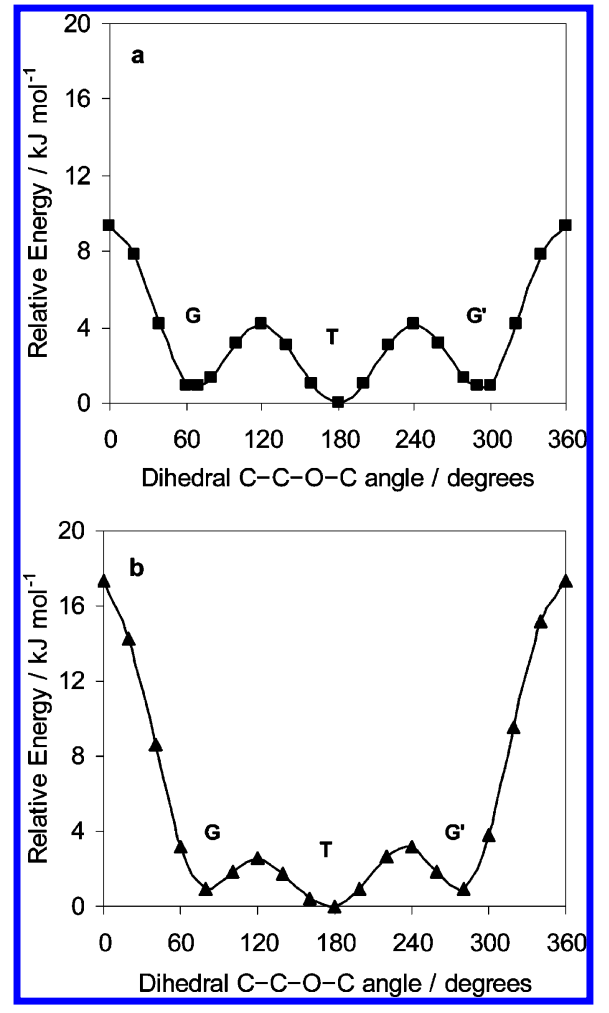

Figure 5. DFT(B3LYP)/6-311++G(d,p) calculated potential energy profiles for internal rotation of the ethoxy group around the $\mathrm{C}_{(4)}-\mathrm{O}_{(1)}$ bond in ethylcyanate (EC) (a) and 3-ethoxy-1-phenyl-1H-diazirene (EPD) (b). The energies of the conformers $\mathbf{T}$ (the lowest energy structures) are equal to -247.338011 and -533.742444 hartrees for EC and EPD, respectively (without the ZPE contribution) and were chosen as the relative zero levels. Minima denoted G, T, and $\mathrm{G}^{\prime}$ on the curve correspond to the lower energy conformers (Tables S6, S7, and S10-S12, Supporting Information).

described as fingerprints of this compound could also be clearly identified in the spectra (Table 2).

Note also that, as found previously for UV irradiation of 5-methoxytetrazole ${ }^{29}$ and 1-phenyltetrazolone monomers isolated in argon, ${ }^{27}$ triplet phenylnitrene (reported to be present in low-temperature matrixes as a result of direct photolysis of isolated phenylazide ${ }^{86}$ ) was not observed in the present study. As previously suggested, ${ }^{27,29}$ the absence of triplet phenylnitrene may result from the fact that phenylazide is produced together with other species and might interact with them in the matrix cage, eventually making inaccessible the pathway which would lead to formation of the triplet nitrene.

In reaction pathway 2 , the extrusion of molecular nitrogen from the tetrazole ring leads to formation of a three-membered heterocyclic ring, namely 3-ethoxy-1-phenyl-1H-diazirene (EPD, Scheme 1), which to the best of our knowledge has never been described before. The elimination of molecular nitrogen after irradiation of tetrazole compounds to give diazirenes has already been described. ${ }^{27,32}$ Diazirenes can be easily identified because their most intense band $(\nu \mathrm{C}=\mathrm{N})$ occurs in a "clean" region of the spectrum $\left(1850-1720 \mathrm{~cm}^{-1}\right)$, appearing as a suitable fingerprint for this family of compounds. In the spectra of the irradiated matrix, the band corresponding to this vibration was clearly identified at $1725 \mathrm{~cm}^{-1}$ (see Table 3 and Figure 4).

Similar to the general picture described above for ethylcyanate, three conformers ( $\left.\mathbf{T}, \mathbf{G}, \mathbf{G}^{\prime}\right)$ separated by low intramolecular energy barriers (less than $3 \mathrm{~kJ} \mathrm{~mol}^{-1}$ ) were also predicted by the calculations for EPD. The potential energy profile for internal rotation around the $-\mathrm{C}_{(4)}-\mathrm{O}-$ axis in EPD is shown in Figure 5 along with that for ethylcyanate. The optimized geometries of the three conformers of EPD, calculated at the DFT(B3LYP)/6-311++G(d,p) level of theory, are included as Supporting Information in Tables S10-S12. Once again, conformational cooling is expected to occur for this species, justifying the observed good agreement between the calculated spectrum of the most stable $\mathbf{T}$ conformer and the experimental data, thus facilitating the interpretation of the photoprocesses occurring in the matrix.

\section{Conclusions}

DFT(B3LYP)/6-311++G(d,p) calculations performed in this study predict that, in the gaseous phase, 5EPT should exist in three different conformers. However, only the most stable of these forms was observed for the compound isolated in an argon matrix at $12 \mathrm{~K}$. The potential energy profile for the internal rotation of the ethyl group in 5EPT was calculated, revealing that the energy barriers separating the two minima of higher energy from the most stable form are very low (less than $4 \mathrm{~kJ}$ $\mathrm{mol}^{-1}$ ). Previous studies show that transitions over such low barriers occur readily during deposition. Thus, it is expected that only the lowest energy $\mathbf{T}$ conformer of 5EPT should be retained in the deposit. After UV irradiation $(\lambda>235 \mathrm{~nm})$ of the matrix, two different reaction pathways could be identified, both corresponding to cleavage of the tetrazole ring: pathway 1 , production of phenylazide and ethylcyanate as primary photoproducts; and pathway 2, molecular nitrogen elimination, leading to formation of the antiaromatic 3-ethoxy-1-phenyl-1 $H$ diazirene (EPD). The primarily formed phenylazide (pathway 1) is partially converted into 1-aza-1,2,4,6-cycloheptatetraene (ACHT), with all probability involving the singlet phenylnitrene as intermediate. The identification of the photoproducts was carried out taking into account both the theoretical spectra for the different putative products and the available literature data on those compounds. The conformational cooling occurrence verified during this work-relaxation of the high energy forms of both reagent (5EPT) and products (ethylcyanate and EPD) into their lower energy structures-facilitated the interpretation of the processes taking place in the matrix.

Acknowledgment. The authors are grateful to Fundação para a Ciência e Tecnologia (FCT) and FEDER for financial support (Project Nos. POCI/QUI/59019/2004 and POCI/QUI/58937/ 2004) and Grants SFRH/BD/17945/2004 (L.M.T.F.) and SFRH/ BPD/1661/2000 (I.D.R.). A.G.-Z. is a member of the Research Career of CONICET (National Research Council, Argentina).

Supporting Information Available: ${ }^{1} \mathrm{H}$ NMR data for 5-ethoxy-1-phenyl-1H-tetrazole (5EPT); Table S1, B3LYP/6$311++\mathrm{G}(\mathrm{d}, \mathrm{p})$ optimized geometries for the most stable conformers of 5EPT; Table S2, definition of internal coordinates used in the normal-coordinate analysis of 5EPT; Tables S3S5, calculated [B3LYP/6-311++G(d,p)] vibrational data for the three low-energy conformers of 5EPT; Tables S6-S12, calculated vibrational data for the different photoproducts of 5EPT (ethylcyanate, phenylazide, 1-aza-1,2,4,6-cycloheptatetraene, 3 -ethoxy-1-phenyl- $1 H$-diazirene). This material is available free of charge via the Internet at http://pubs.acs.org.

\section{References and Notes}

(1) Herr, R. J. Bioorg. Med. Chem. 2002, 10, 3379

(2) Noda, K.; Saad, Y.; Kinoshita, A.; Boyle, T. P.; Graham, R. M.; Husain, A.; Karnik, S. S. J. Biol. Chem. 1995, 270, 2284.

(3) Herbst, R. M.; Wilson, K. R. J. Org. Chem. 1957, 22, 1142.

(4) Ostrovskii, V. A.; Koren, A. O. Heterocycles 2000, 53, 1421. 
(5) Kaczmarek, J.; Smagowski, H.; Grzonka, Z. J. Chem. Soc., Perkin Trans. 2 1979, 1670.

(6) Schaaf, T. K.; Hess, H. J. J. Med. Chem. 1979, 22, 1340.

(7) McManus, J. M.; Herbst, R. M. J. Org. Chem. 1959, 24, 1643.

(8) Thornber, C. W. Chem. Soc. Rev. 1979, 8, 563.

(9) Butler, R. N. Adv. Heterocycl. Chem. 1977, 21, 323.

(10) Wittenberger, S. J. Org. Prep. Proced. Int. 1994, 26, 499

(11) Burger, A. Prog. Drug Res. 1991, 37, 287.

(12) Teixeira-Dias, J. J. C.; Fausto, R. J. Mol. Struct. 1986, 199.

(13) Mavromoustakos, T.; Kolocouris, A.; Zervou, M.; Roumelioti, P.; Matsoukas, J.; Weisemann, R. J. Med. Chem. 1999, 42, 1714.

(14) Toney, J. H.; Fitzgerald, P. M. D.; Grover-Sharma, N.; Olson, S. H.; May, W. J.; Sundelof, J. G.; Vanderwall, D. E.; Cleary, K. A.; Grant, S. K.; Wu, J. K.; Kozarich, J. W.; Pompliano, D. L.; Hammond, G. G. Chem. Biol. 1998, 5, 185 .

(15) Hashimoto, Y.; Ohashi, R.; Kurosawa, Y.; Minami, K.; Kaji, H.; Hayashida, K.; Narita, H.; Murata, S. J. Cardiovasc. Pharmacol. 1998, 31, 568.

(16) Desarro, A.; Ammendola, D.; Zappala, M.; Grasso, S.; Desarro, G. B. Antimicrob. Agents Chemother. 1995, 39, 232.

(17) Tamura, Y.; Watanabe, F.; Nakatani, T.; Yasui, K.; Fuji, M.; Komurasaki, T.; Tsuzuki, H.; Maekawa, R.; Yoshioka, T.; Kawada, K.; Sugita, K.; Ohtani, M. J. Med. Chem. 1998, 41, 640.

(18) Abell, A. D.; Foulds, G. J. J. Chem. Soc., Perkin Trans. 1 1997, 2475.

(19) Sandmann, G.; Schneider, C.; Boger, P. Z. Naturforsch., C 1996, 51,534

(20) Koldobskii, G. I.; Ostrovskii, V. A.; Poplavskii, V. S. Khim. Geterotsikl. Soedin. 1981, 1299.

(21) Zhao-Xu, C.; Heming, X. Int. J. Ouantum Chem. 2000, 79, 350. (22) Dunkin, I. R.; Shields, C. J.; Quast, H. Tetrahedron 1989, 45, 259.

(23) Maier, G.; Eckwert, J.; Bothur, A.; Reisenauer, H. P.; Schmidt, C. Liebigs Ann. 1996, 1041

(24) Awadallah, A.; Kowski, K.; Rademacher, P. J. Heterocycl. Chem.

1997, 34, 113

(25) Frija, L. M. T.; Khmelinskii, I. V.; Cristiano, M. L. S. J. Org. Chem 2006, 71, 3583

(26) Frija, L. M. T.; Khmelinskii, I. V.; Cristiano, M. L. S. Tetrahedron Lett. 2005, 46, 6757.

(27) Gómez-Zavaglia, A.; Reva, I. D.; Frija, L.; Cristiano, M. L.; Fausto, R. J. Photochem. Photobiol., A: Chem. 2006, 179, 243.

(28) Gómez-Zavaglia, A.; Reva, I. D.; Frija, L.; Cristiano, M. L.; Fausto,

R. J. Mol. Struct. 2006, 786, 182

(29) Gómez-Zavaglia, A.; Reva, I. D.; Frija, L.; Cristiano, M. L. S.; Fausto, R. J. Photochem. Photobiol., A: Chem. 2006, 180, 175.

(30) Gómez-Zavaglia, A.; Reva, I. D.; Frija, L.; Cristiano, M. L.; Fausto, R. J. Phys. Chem. A 2005, 109, 7967.

(31) Bugalho, S. C. S.; Serra, A. C.; Lapinski, L.; Cristiano, M. L. S.; Fausto, R. Phvs. Chem. Chem. Phvs. 2002, 4, 1725.

(32) Bugalho, S. C. S.; Lapinski, L.; Cristiano, M. L. S.; Frija, L. M.

T.; Fausto, R. Vib. Spectrosc. 2002, 30, 213.

(33) Bugalho, S. C. S.; Macôas, E. M. S.; Cristiano, M. L. S.; Fausto, R. Phvs. Chem. Chem. Phvs. 2001, 3, 3541.

(34) Smirnova, G. G.; Kovaleva, O. P.; Artamonova, T. V.; Koreneva, A. P.; Koldobskii, G. I. Russ. J. Org. Chem. 2003, 39, 1679. 2110.

(35) Demko, Z. P.; Sharpless, K. B. Angew. Chem. Int. Ed. 2002, 41,

(36) Cristiano, M. L. S. Ph.D. Thesis, University of Liverpool, 1994.

(37) Vollmar, A.; Hassner, A. J. Heterocycl. Chem. 1974, 11, 491.

(38) Reva, I. D.; Stepanian, S. G.; Adamowicz, L.; Fausto, R. J.Phvs. Chem. A 2001, 105, 4773.

(39) Becke, A. D. Phvs. Rev. A 1988, 38, 3098.

(40) Lee, C. T.; Yang, W. T.; Parr, R. G. Phvs. Rev. B 1988, 37, 785

(41) Schachtschneider, J. H. Technical Report; Shell Development Co. Emeryville, CA, 1969.

(42) Pulay, P.; Fogarasi, G.; Pang, F.; Boggs, J. E. J.Am. Chem. Soc. 1979, 101, 2550.

(43) Frisch, M. J.; Trucks, G. W.; Schlegel, H. B.; Scuseria, G. E.; Robb M. A.; Cheeseman, J. R.; Montgomery, J. A., Jr.; Vreven, T.; Kudin, K. N.; Burant, J. C.; Millam, J. M.; Iyengar, S. S.; Tomasi, J.; Barone, V.; Mennucci, B.; Cossi, M.; Scalmani, G.; Rega, N.; Petersson, G. A.; Nakatsuji, H.; Hada, M.; Ehara, M.; Toyota, K.; Fukuda, R.; Hasegawa, J.; Ishida, M.; Nakajima, T.; Honda, Y.; Kitao, O.; Nakai, H.; Klene, M.; Li, X.; Knox, J. E.; Hratchian, H. P.; Cross, J. B.; Bakken, V.; Adamo, C.; Jaramillo, J.; Gomperts, R.; Stratmann, R. E.; Yazyev, O.; Austin, A. J.; Cammi, R.; Pomelli, C.; Ochterski, J. W.; Ayala, P. Y.; Morokuma, K.; Voth, G. A.; Salvador, P.; Dannenberg, J. J.; Zakrzewski, V. G.; Dapprich, S.; Daniels, A. D.; Strain, M. C.; Farkas, O.; Malick, D. K.; Rabuck, A. D.; Raghavachari, K.; Foresman, J. B.; Ortiz, J. V.; Cui, Q.; Baboul, A.
G.; Clifford, S.; Cioslowski, J.; Stefanov, B. B.; Liu, G.; Liashenko, A.; Piskorz, P.; Komaromi, I.; Martin, R. L.; Fox, D. J.; Keith, T.; Al-Laham, M. A.; Peng, C. Y.; Nanayakkara, A.; Challacombe, M.; Gill, P. M. W.; Johnson, B.; Chen, W.; Wong, M. W.; Gonzalez, C.; Pople, J. A. Gaussian 03, revision C.02; Gaussian, Inc.: Wallingford, CT, 2004

(44) Barnes, A. J. J. Mol. Struct. 1984, 113, 161

(45) Jesus, A. J. L.; Rosado, M. T. S.; Reva, I.; Fausto, R.; Eusébio, M. E.; Redinha, J. S. J. Phvs. Chem. A 2006, 110, 4169.

(46) Reva, I.; Simão, A.; Fausto, R. Chem. Phvs. Lett. 2005, 406, 126

(47) Reva, I. D.; Jesus, A. J. L.; Rosado, M. T. S.; Fausto, R.; Eusébio,

M. E.; Redinha, J. S. Phys. Chem. Chem. Phvs. 2006, 8, 5339.

(48) Reva, I. D.; Stepanian, S. G.; Adamowicz, L.; Fausto, R. Chem. Phvs. Lett. 2003, 374, 631.

(49) Borba, A.; Gómez-Zavaglia, A.; Fausto, R. J. Mol. Struct. 2006, 794, 196.

(50) Borba, A.; Gómez-Zavaglia, A.; Simões, P. N. N. L.; Fausto, R. $J$. Phvs. Chem. A 2005, 109, 3578 .

(51) Catalan, J.; dePaz, J. L. G.; delValle, J. C.; Kasha, M. J. Phvs. Chem. A 1997, 101, 5284

(52) Lynch, D. E.; McClenaghan, I. Acta Crvstallogr., Sect. E.: Struct. Rep. Online 2001, 57, o264.

(53) Damrauer, N. H.; McCusker, J. K. J. Phys. Chem. A 1999, 103 , 8440

(54) Cyranski, M. K.; Mieczkowski, J. Acta Crystallogr., Sect. C: Cryst. Struct. Commun. 1998, 54, 1521

(55) Matsunaga, T.; Ohno, Y.; Akutsu, Y.; Arai, M.; Tamura, M.; Iida, M. Acta Crvstallogr., Sect. C: Crvst. Struct. Commun. 1999, 55, 129.

(56) Zukermanschpector, J.; Barreiro, E. J.; Freitas, A. C. C. Acta Crustallogr. Sect. C: Crust. Struct. Commun. 1994, 50, 2095.

(57) Kowalski, A. Acta Crvstallogr. Sect. C: Crvst. Struct. Commun.

$1995,51,1670$

(58) Damrauer, N. H.; Weldon, B. T.; McCusker, J. K. J. Phvs. Chem. A 1998, 102, 3382.

(59) Batista de Carvalho, L. A. E.; Teixeira-Dias, J. J. C.; Fausto, R Struct. Chem. 1990, 1, 533 .

(60) Pearson, R.; Lovas, F. J. J. Chem. Phvs. 1977, 66, 4149

(61) Billes, F.; Mikosch, H.; Holly, S. Theochem 1998, 423, 225.

(62) Boese, A. D.; Martin, J. M. L. J. Phvs. Chem. A 2004, 108, 3085.

Martin, J. M. L.; Van Alsenoy, C. J. Phvs. Chem. 1996, 100, 6973.

(63) Breda, S.; Reva, I. D.; Lapinski, L.; Nowak, M. J.; Fausto, R. J. Mol. Struct. 2006, 786, 193.

(64) Chae, Y. B.; Chang, K. S.; Kim, S. S. Daehan Hwak Hwoejee 1967, 11,85

(65) Quast, H.; Bieber, L. Angew. Chem., Int. Ed. Engl. 1975, 14, 428

(66) Quast, H.; Bieber, L. Chem. Ber.-Recl. 1981, 114, 3253.

(67) Quast, H.; Fuss, A.; Nahr, U. Chem. Ber.-Recl. 1985, 118, 2164.

(68) Quast, H.; Nahr, U. Chem. Ber.-Recl. 1985, $118,526$.

(69) Quast, H. Heterocycles 1980, 14, 1677.

(70) Patai, S. The Chemistry of Cyanates and their Thio Derivatives;

Wiley: New York, 1977.

(71) Martin, D.; Niclas, H. J.; Habisch, D. Justus Liebigs Ann. Chem 1969, 727,10

(72) Aljuaid, S. S.; Alnasr, A. A. K.; Ayoko, G. A.; Eaborn, C.; Hitchcock, P. J. Organomet. Chem. 1995, 488, 155 .

(73) Eaborn, C.; Lickiss, P. D.; Marquinachidsey, G.; Thorli, E. Y. J. Chem. Soc. Chem. Commun. 1982, 1326.

(74) Martin, D. Tetrahedron Lett. 1964, 2829.

(75) Martin, D.; Weise, A. Chem. Ber.-Recl. 1966, 99, 976.

(76) Holm, A.; Hugejens, E. Acta Chem. Scand., Ser. B: Org. Chem. Biochem. 1974, B28, 705 .

(77) Fischer, H.; Zeuner, S.; Ackermann, K.; Schubert, U. J. Organomet Chem. 1984, 263, 201.

(78) Groving, N.; Holm, A. Acta Chem. Scand. 1965, 19, 443.

(79) Reich, P.; Martin, D. Chem. Ber.-Recl. 1965, 98, 2063.

(80) Jensen, K. A.; Holm, A.; Wentrup, C. Acta Chem. Scand. 1966 20, 2107.

(81) Sakaizumi, T.; Mure, H.; Ohashi, O.; Yamaguchi, I. J. Mol. Spectrosc. 1989, 138, 375 .

(82) Pasinszki, T.; Havasi, B.; Kovacs, A. J. Phys. Chem. A 2003, 107, 1720

(83) Jensen, K. A.; Due, M.; Holm, A. Acta Chem. Scand. 1965, 19 , 438

(84) Teixeira-Dias, J. J. C.; Fausto, R. J. Mol. Struct. 1986, 144, 199.

(85) Tomioka, H.; Ichikawa, N.; Komatsu, K. J. Am. Chem. Soc. 1993 115, 8621; Carra, C.; Bally, T.; Albini, A. J. Am. Chem. Soc. 2005, 127, 5552; Morawietz, J.; Sander, W. J. Org. Chem. 1996, 61, 4351; Hill, B. T.; Platz, M. S. Phys. Chem. Chem. Phys. 2003, 5, 1051; and references therein. 5879
(86) Hayes, J. C.; Sheridan, R. S. J. Am. Chem. Soc. 1990, 112, 